\title{
Çocukluk Çağı Meme Kitlelerinde Güncel Cerrahi Yaklaşım
}

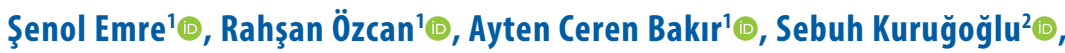 \\ Nil Çomunoğlu ${ }^{3} \odot$, Gonca Topuzlu Tekant ${ }^{1}$ (])
}

1'istanbul Üniversitesi Cerrahpaşa Tıp Fakültesi, Çocuk Cerrahisi, İstanbul, Türkiye

2̇stanbul Üniversitesi Cerrahpaşa Tıp Fakültesi, Radyoloji, İstanbul, Türkiye 3̇stanbul Üniversitesi Cerrahpaşa Tıp Fakültesi, Patoloji, İstanbul, Türkiye

Şenol Emre, Doç. Dr. Rahşan Özcan, Doç. Dr. Ayten Ceren Bakır, Uzm. Dr. Sebuh Kuruğoğlu, Prof. Dr. Nil Çomunoğlu, Prof. Dr. Gonca Topuzlu Tekant, Prof. Dr.

Illetişim:

Doç. Dr. Rahşan Özcan

İstanbul Üniversitesi Cerrahpaşa Tıp Fakültesi, Çocuk Cerrahisi, İstanbul, Türkiye

Tel: +902124143314

E-Posta: rozcan1@gmail.com
Gönderilme Tarihi : 11 Temmuz 2018

Revizyon Tarihi : 09 Ağustos 2018

Kabul Tarihi $\quad$ : 07 Eylül 2018

\section{ÖZET}

Amaç: Çocukluk çağı meme kitlelerinde cerrahi yaklaşımın değerlendirilmesidir.

Hastalar ve Yöntemler: 2005-2017 yılları arasında meme kitlesi nedeni ile cerrahi girişim yapılan olgular geriye dönük olarak incelendi. Yaş, primer tanı, radyolojik özellikler, cerrahi tedavi yöntemi, komplikasyonlar, hastanede kalış süresi ve takip açısından değerlendirildi.

Bulgular: Memede kitle nedeniyle cerrahi yapılan 29 olgunun yaş ortalaması 14,86 yaş (6-17 yaş) idi. En sık başvuru yakınması memede ele gelen kitle idi. İki olguda ayrıca kanlı meme başı akıntısı mevcuttu. Semptomların süresi ortalama 32,3 hafta (2 hafta-1 yil) olarak bulundu. Altı olguda $(\% 20,6)$ meme hastalığı ile ilgili aile hikayesi mevcuttu. Ortalama BMi 18,8 (15,8-24) idi. Lezyonların $15^{\prime}$ i sol, $13^{\prime}$ ï sağ ve 1'i bilateral yerleşimliydi.

Radyolojik değerlendirme için olguların tümüne ultrasonografi (USG), 5'ine ek olarak magnetik rezonans görüntüleme (MRG) yapıldı. Radyolojik olarak ölçülen kitle boyutu ortalama $2,9 \mathrm{~cm}(0,9-7 \mathrm{~cm})$ idi. Beş olguda birden fazla lezyon mevcuttu. Altı olguya malignite şüphesi ile preoperatif dönemde iğne biyopsisi yapıldı ve hepsi fibroadenom ile uyumlu bulundu.

Cerrahi eksizyon sonrası yapılan histopatolojik incelemede fibroadenom (n:26), borderline filloides tümörü (n:1), meme başı duktus adenomu (n:1) ve galaktosel (n:1) saptandı.

Ortalama takip zamanı 36,6 ay ( 3 ay-10 yıl) idi. Takipte olguların 3'ünde aynı tarafta, 1 'ünde karşı tarafta yeni lezyonlar ortaya çıtı ve takibe alındı.

Sonuç: Çocukluk çă̆ı meme kitlelerinin çoğu benigndir. Nadiren de olsa malignite görülmesi nedeniyle klinik muayene ve ultrasonografinin şüpheli olduğu olgularda MRG yapılması ve iğne biyopsisi alınması doğru cerrahi planlanma için gereklidir.

Anahtar sözcükler: Meme, kitle, fibroadenom, çocuk, cerrahi

\section{CURRENT SURGICAL APPROACH TO BREAST MASSES IN CHILDHOOD}

\section{ABSTRACT}

Objectives: To evaluate the surgical approach to pediatric breast masses.

Patients and Methods: Patients who underwent a surgical intervention due to breast mass between the years of 2005-2017 were evaluated retrospectively. They were evaluated in terms of age, primary diagnosis, radiological characteristics, surgical treatment method, complications, length of hospital stay and follow-up.

Results: The mean age of the 29 cases that were operated on for a breast mass was 14.86 years (6-17 years). The most common complaint at admission was a palpable breast mass. Two cases had bloody discharge from the nipple. The mean duration of the symptoms was 32.3 weeks ( 2 weeks-1 year). Six cases (20.6\%) had a family history associated with breast disease. The mean BMI was 18.8 (15.8-24). In 15 patients, the mass was in the left breast, whereas in 13 patients, the mass was in the right breast. However, in one case, two masses were localized bilaterally.

Regarding radiological examination, ultrasonography (USG) was performed on all patients while magnetic resonance imaging (MRI) was obtained as a supplement in five cases. The mean size of the masses measured radiologically was $2.9 \mathrm{~cm}(0.9-7 \mathrm{~cm})$. There were multiple lesions in five cases. Needle biopsy was performed in six cases with the suspicion of malignancy in the preoperative period, and they were all found to be consistent with fibroadenoma.

Histopathological examination was performed after the surgical excision and revealed fibroadenoma ( $\mathrm{n}: 26)$, borderline phylloides $(n: 1)$, nipple adenoma ( $n: 1)$ and galactocele ( $n: 1)$.

The mean follow-up period was 36.6 months ( 3 months- 10 years). New lesions were developed ipsilaterally in three cases and contralaterally in one case during follow-up.

Conclusion: Most of pediatric breast masses are benign. Although malignancy is rarely encountered, MRI and needle biopsy are required for accurate surgical planning in case of suspicious ultrasonography findings.

Keywords: Breast, mass, fibroadenoma, child, surgery 
$\mathbf{M}$ eme kitleleri çocukluk çağında nadir görülür Çoğu benign karakterde olan fibroadenomlardır. Fibroadenomların maligniteye dönüşme olasılığı \%0.3 olarak bildirilmektedir. Malign meme kitleleri ise tüm çocukluk çağı kanserlerinin \%1'inden azını kapsamaktadır (1).

Meme kitlelerinin tanısında fizik muayene yanında ultrasonografi (USG), magnetik rezonans görüntüleme (MRG), mammografi, iğne biyopsisi ve eksizyonel biyopsiden yararlanılmaktadır. USG meme lezyonlarını değerlendirmede en sık kullanılan görüntüleme yöntemidir Mammografi, çocukluk çağında meme dansitesinin yüksek olması ve radyasyon maruziyeti nedeni ile kullanılmamaktadır (2).

Çocukluk çağı meme kitlelerinin davranış biçimi erişkinlerden farklı olduğu için tedavi yaklaşımları da farklılık göstermektedir. Genellikle benign karakterde olan çocukluk çağı meme kitleleri kendiliğinden gerileme özelliğine sahiptir $(1,3,4)$. Ancak klinik ve radyolojik bulgularda şüphe olan olguların iyi değerlendirilmesi ve uygun cerrahi tedavinin yapılması önem taşımaktadır. Çalışmanın amacı kliniğimizde memede kitle nedeni ile cerrahi girişim yapılan olguların tanı aşamalarının ve tedavi sonuçlarının değerlendirilmesidir.

\section{Olgular ve yöntem}

2005-2017 yılları arasında meme kitlesi nedeni ile cerrahi girişim yapılan kız olgular geriye dönük olarak incelendi. Olgular yaş, başvuru yakınması, semptomların süresi, klinik bulgular, menstruasyon durumu, vücut kitle indeksi, aile hikayesi varlığı, radyolojik özellikler, tedavi yöntemi, komplikasyonlar, hastanede kalış süresi ve takip açısından değerlendirildi.

Tüm olgulara ilk radyolojik inceleme olarak USG yapıldı. USG'de fibroadenom düşündüren bulgular oval/yuvarlak iyi sınırlı kitle varlığı, kitlenin uzun aksının cilde paralel olması ve makrolobulasyon varlığı idi. Fizik muayene ve USG bulgularında malignite şüphesi olan olgulara MRG ve iğne biyopsisi de yapılarak cerrahi öncesi değerlendirme gerçekleştirildi.

Cerrahi işlem tüm olgularda kitle eksizyonu şeklinde idi. Hiçbir olguda geniş eksizyon, mastektomi ve lenf nodu diseksiyonu uygulanmadı. Tüm olgularda eksizyon işlemi sirkumareolar insizyon ile yapıldı (Şekil 1).

\section{Bulgular}

Memede kitle nedeni cerrahi yapılan 29 olgunun yaş ortalaması 14,86 yaş (6-17 yaş) idi. Olguların özellikleri Tablo 1 'de özetlenmiştir.

Radyolojik değerlendirme için olguların tümüne USG yapıldı. Malignite şüphesi olan 5 olguya ek olarak MRG de yapıldı. Memede saptanan lezyonların özellikleri ve yerleşim yerleri Tablo 2 ve Şekil 2'de özetlenmiştir.

Olguların klinik ve radyolojik değerlendirmeleri sonrasında 23 olguda benign lezyon düşünülerek cerrahi eksizyon uygulandı. Geri kalan 6 hastada aile hikayesi olması,
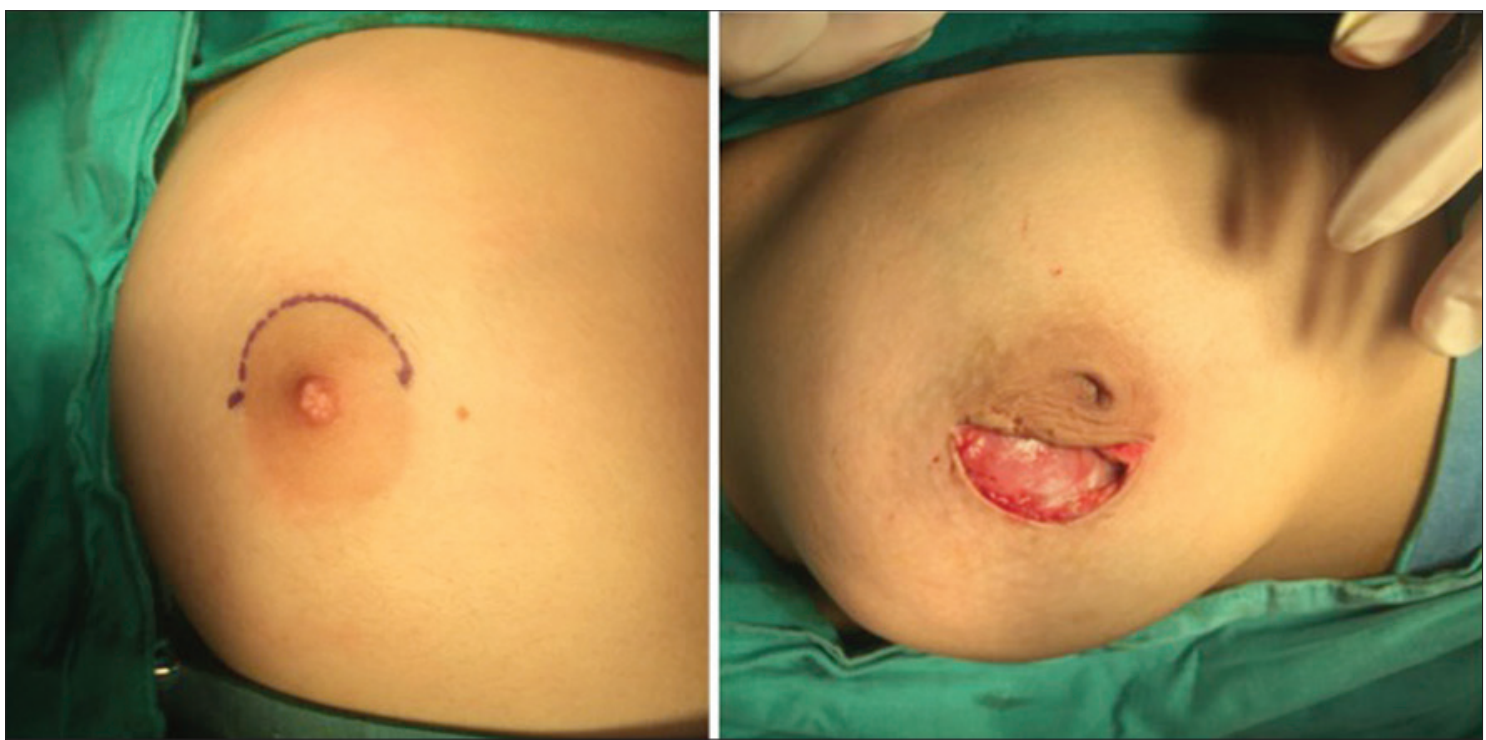

Şekil 1. Meme lezyonlarının yerleşim bölgeleri 
Tablo 1. Olguların demografik özellikleri

\begin{tabular}{lc} 
Olgu sayısı (n) & 29 \\
\hline Yaş ortalaması & 14.86 yaş (6-17 yaş) \\
Başvuru semptomları(n) & 26 \\
$\quad$ kitle & 2 \\
$\quad$ meme başında akıntı & 2 \\
$\quad$ memede şekil bozukluğu & 3 \\
$\quad$ ağıı & \\
Menstruasyon Durumu(n) & 2 \\
$\quad$ Prepubertal & 27 \\
$\quad$ Postpubertal & 6 \\
Aile Hikayesi(n) & $18,8(15,8-24)$ \\
Vücut Kitle İndeksi(VKi) & 32,3 hafta (2 hafta-1 yıl) \\
Semptomların Süresi &
\end{tabular}

Tablo 2. Meme lezyonlarının özellikleri

\begin{tabular}{lc} 
Lezyonların Özellikleri & \\
\hline Radyolojik İnceleme(n) & \\
USG & 29 \\
MR & 5 \\
Taraf(n) & \\
Sol & 15 \\
Sağ & 13 \\
Bilateral & 1 \\
Boyut & $2,9 \mathrm{~cm}(0,9-7 \mathrm{~cm})$ \\
Sayı(n) & $34(5$ olguda 2 lezyon $)$
\end{tabular}

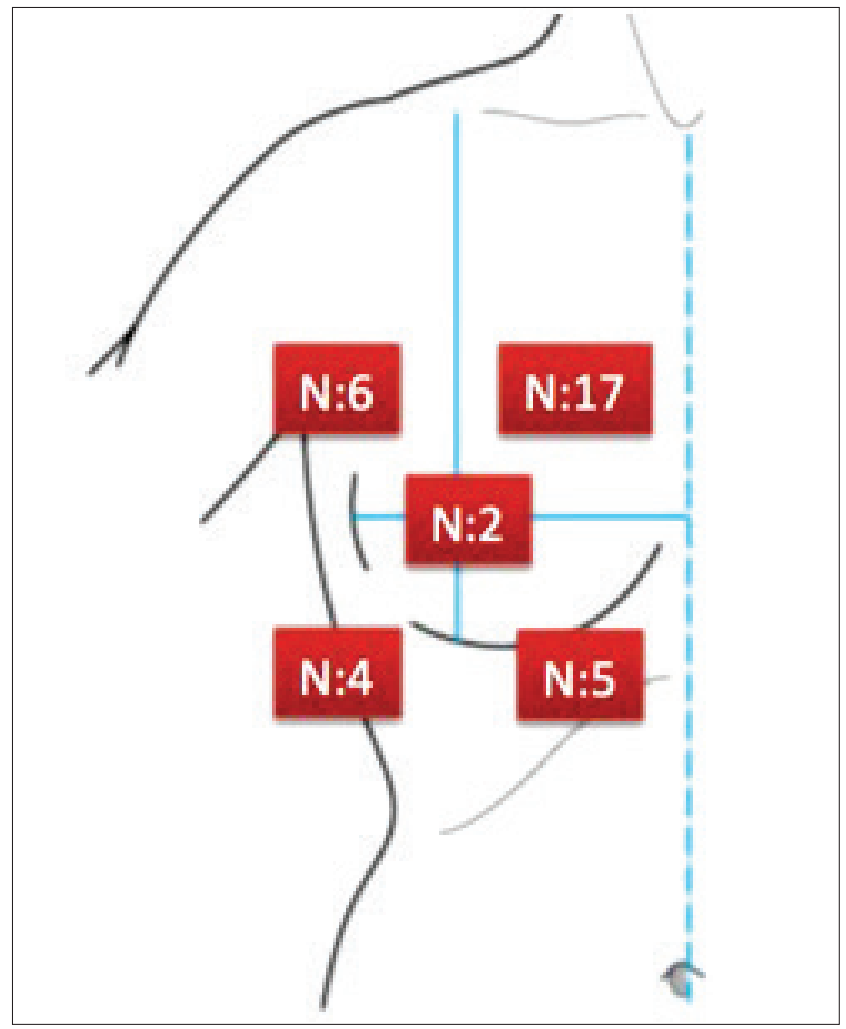

Şekil 2. Meme kitlelerinin eksizyonunda kullanılan sirkumareolar insizyon meme başında şekil bozukluğu, kanlı akıntı saptanması ve malignite düşündüren radyolojik bulgulardan bir veya birkaçı olması nedeniyle öncelikle iğne biyopsisi yapıldı (Şekil 3).

Histopatolojik incelemede fibroadenom (n:26), borderline filloides tümörü (n:1), meme başı duktus adenomu (n:1) ve galaktosel (n:1) saptandı (Şekil 4). Borderline filloides tümörü olan olguda hafif hücresel atipi, düşük mitoz sayısı olması nedeniyle yakın takibe alınarak ek cerrahi girişim uygulanmadı.

Ortalama takip zamanı 36,6 ay (3 ay-10 yı) idi. Takipte olguların 3'ünde aynı tarafta, 1'inde karşı tarafta yeni lezyonlar ortaya çıktı ve malign özellik taşımadığı için bu olgular halen takip edilmektedir.

\section{Tartışma}

Çocukluk çağında görülen meme kitlelerinin büyük çoğunluğu benigndir. Benign kitlelerin \%54-94'ünü fibroadenomlar oluşturmaktadır (5). Fibroadenomların görülme yaşı genellikle 14-15 yaşlarında pik yapmaktadır. Fizik muayenede sert, düzgün sınırlı kitleler şeklindedir. Sıklıkla üst-dış kadranda yerleşen fibroadenomların boyutları menstruasyon ile değişiklik gösterebilir. Filloides tümörler ise meme tümörlerinin \%0.3-1'ini oluşturan nadir fibroepitelyal tümörlerdir. Benign, borderline ve malign alt tipleri bulunmaktadır (6). Bazı filloides tümörler nüks ve metastazlara yol açabilir. Özellikle patolojik incelemede sarkomatöz yapılar içeren, stromal hücrelerde atipisi olan ve infiltratif sınırları olan filloides tümörlerde nüks olasılığı yüksektir. Malign filloides tümörlerde nüks oranları $\% 40$ 'ların üzerinde bildirilmektedir (7). Bizim serimizde de olguların \%90'ında fibroadenom saptanmıştır. Sadece bir olguda (\%3.5) borderline filloides tümör bulunmuştur.

Çocukluk çağı fibroadenomları kendiliğinden gerileme özelliğine sahip olduğu için konservatif yaklaşım önerilmektedir. Ancak klinik ve radyolojik olarak fibroadenom ve filloides tümörleri ayırt edebilecek net kriterler yoktur. Meme kitlelerinin tanısında ilk kullanılan ve en güvenilir radyolojik görüntüleme yöntemi USG'dir. USG tanıda, kitlenin takibinde ve biyopsi sırasında yardımcıdır $(7,8)$. Fibroadenomlar USG'de tipik olarak kapsüllü, oval/yuvarlak iyi sınırlı, lobule ve uzun aksı cilde paralel kitleler şeklinde görülür. Düzensiz şekil, uzun aksı cilde paralel yerleşmeyen kitle, keskin olmayan kenar, posterior akustik gölgelenme ise USG'de malignite düşündüren bulgulardır(9). Meme kitlelerinin tanısında MRG'nin yeri sınırlıdır. USG'de kuvvetle malignite düşünülen olgularda cerrahi 


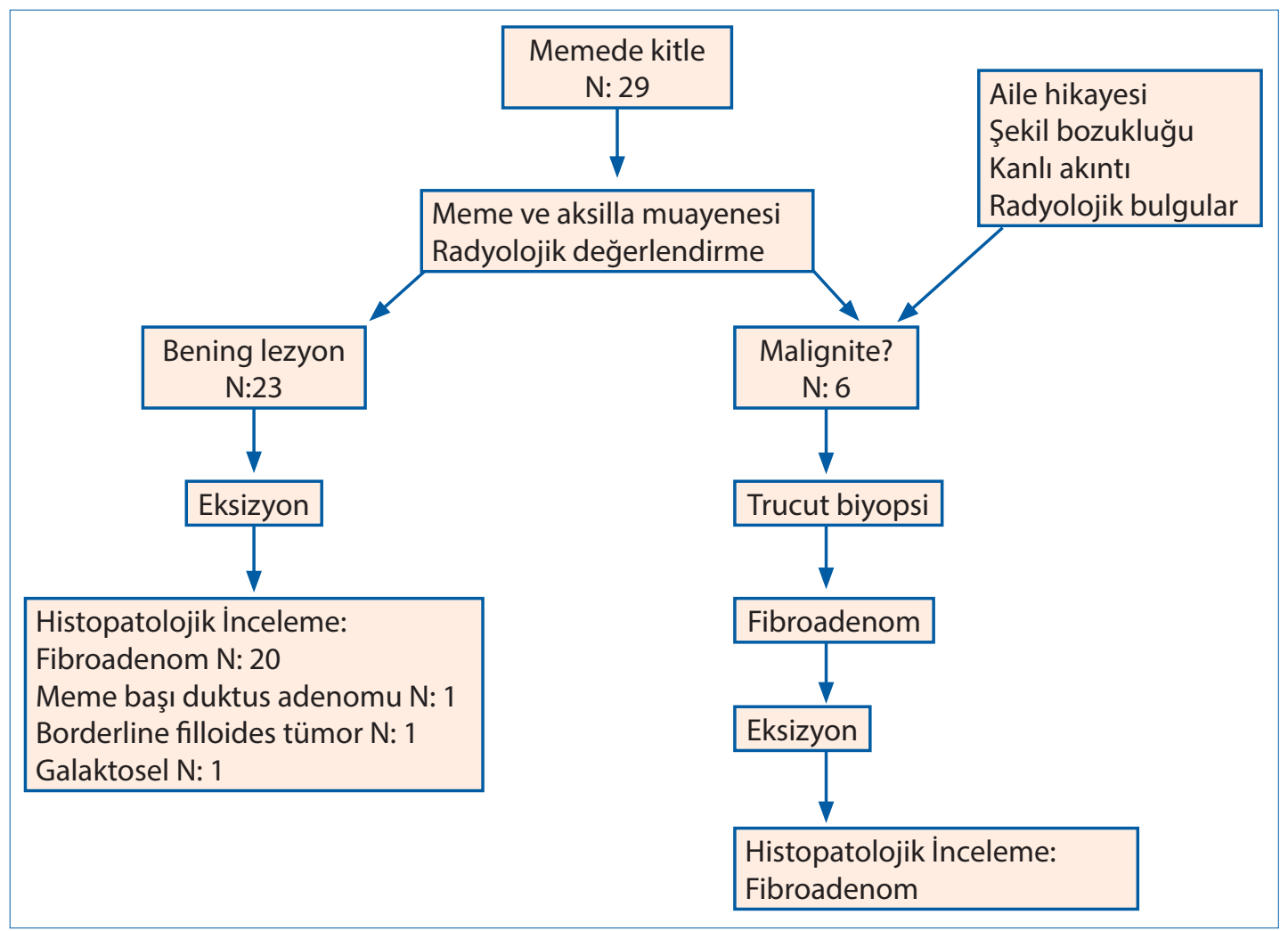

Şekil 3. Olguların tedavi algoritması ve histopatolojik inceleme sonuçları
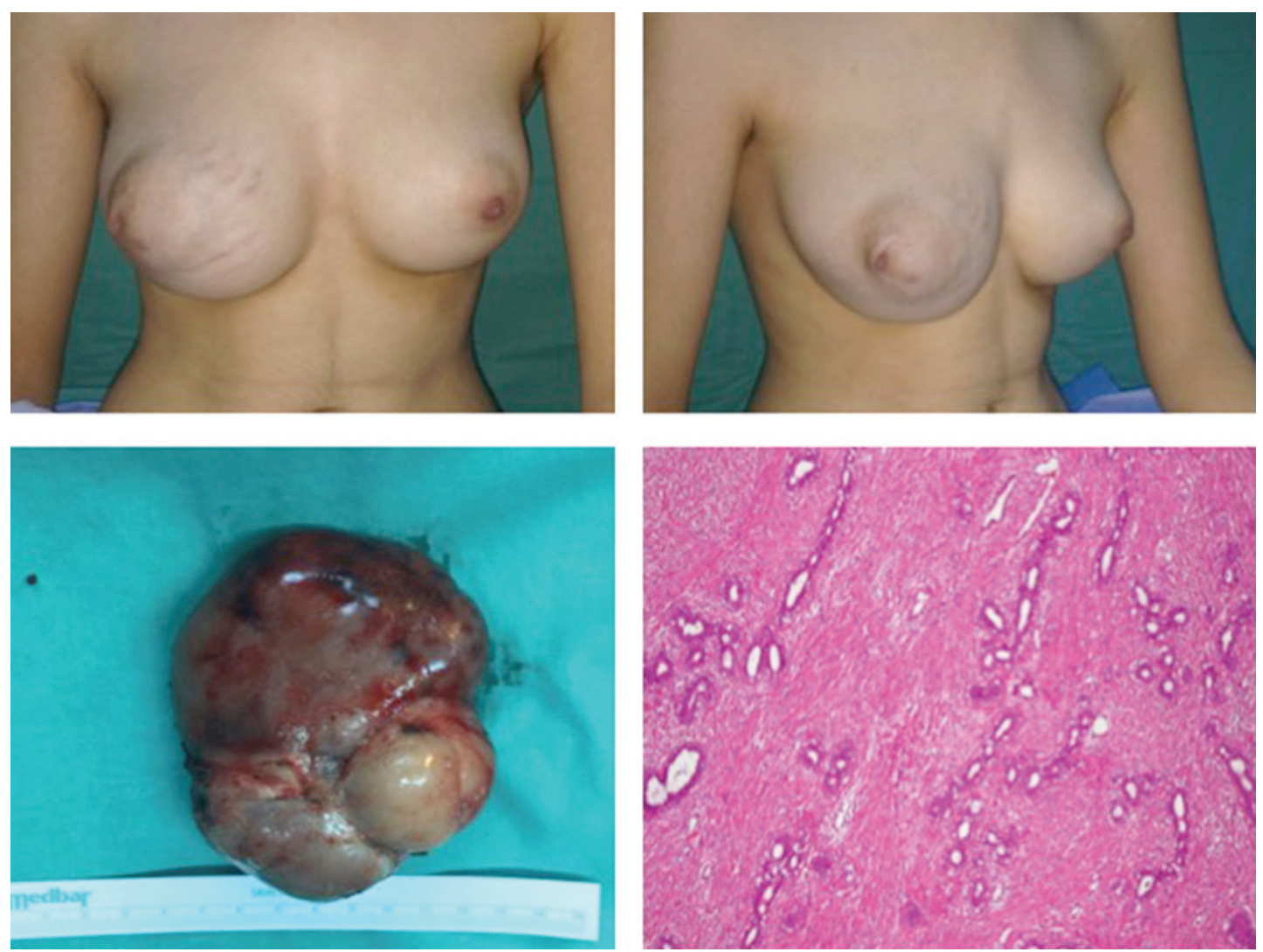

Şekil 4. Sağ memede kitle ile başvuran olguda çıkrılan kitle patolojisi fibroadenom idi. H\&E ile 100’lük büyütmede fibroadenom ile uyumlu bulgular saptandı. 
sınırı belirleme ve metastatik hastalık varlığını değerlendirmede kullanılır. Bizim serimizde tüm olgulara ilk olarak USG yapılmıştır. USG'de malignite düşündüren bulgulara sahip olan 5 olguya ek olarak MRG de yapılmış, ancak bu olguların histopatolojik değerlendirmeleri sonucunda benign lezyon (fibroadenom) saptanmıştır. USG'de benign patoloji düşünülen olgulardan birinde ise histopatolojik incelemede borderline filloides tümör tespit edilmiştir. Bu veriler radyolojik bulguların histopatolojik bulgular ile birlikte değerlendirildiğinde kesin tanıda daha güvenilir olduğunu düşündürmektedir.

Meme kitlelerinde benign/malign ayrımı yapmak için iğne biyopsisinden yararlanılabilir. Radyolojik ve klinik bulgular ile birlikte değerlendirildiğinde iğne biyopsisi lezyonun takibi ya da cerrahi çıkarılması için karar verilmesini sağlar. Ayrıca iğne biyopsisinde malignite saptanması önceden cerrahi planlamanın yapılması ve tekrarlayan cerrahilerin önlenmesi açısından önemlidir $(10,11)$. Çalışmamızda malignite düşünülen 6 olguya yapılan iğne biyopsisinde fibroadenom saptanmış ve kitlelerin enükleasyonu cerrahi tedavi için yeterli olmuştur.

\section{Kaynaklar}

1. Knell J, Koning JL, Grabowski JE. Analysis of surgically excised breast masses in 119 pediatric patients. Pediatr Surg Int. 2016;32:93-6. [CrossRef]

2. Tiryaki T, Senel E, Hucumenoglu S, Cakir BC, Kibar AE. Breast fibroadenoma in female adolescents. Saudi Med J. 2007;28:137-8.

3. Durmaz E, Öztek MA, Arı̈̈z Habibi H, Kesimal U, Sindel HT. Breast diseases in children: the spectrum of radiologic findings in a cohort study. Diagn Interv Radiol. 2017;23:407-13. [CrossRef]

4. Tea MK, Asseryanis E, Kroiss R, Kubista E, Wagner T. Surgical breast lesions in adolescent females. Pediatr Surg Int. 2009; 25:73-5. [CrossRef]

5. Karadağ ÇA. Breast Masses in Chilhood. Turkiye Klinikleri J Pediatr Surg-Special Topics 2015;5:39-46

6. Chao TC, Lo YF, Chen SC, Chen MF. Sonographic features of phyllodes tumors of the breast. Ultrasound Obstet Gynecol. 2002;20:64-71. [CrossRef]

7. Kaneda HJ, Mack J, Kasales CJ, Schetter S. Pediatric and adolescent breast masses: a review of pathophysiology, imaging, diagnosis, and treatment. AJR Am J Roentgenol. 2013;200:204-12. [CrossRef]
Çocukluk çağında meme kitlelerinde hangi hastaya cerrahi eksizyon yapılacağı tartışmalıdır. Genel yaklaşım yakın takip edilmesi yönündedir. Ancak hızıı büyüme eğiliminde olan, $5 \mathrm{~cm}$.den büyük, sebat eden ya da regrese olmayan kitle varlığı, malignite ya da radyasyon hikayesi, ailede meme kanseri hikayesi ve radyolojik bulgularda şüphe olan olgularda cerrahi eksizyon yönünde düşünülmelidir $(1,2,3)$. Çalışmamızda en sık cerrahi endikasyon sebat eden kitle ve malignite şüphesi olarak saptanmıştır. Önerilen cerrahi yaklaşım benign lezyonlarda sirkumareolar ya da inframammary insizyon ile lokal eksizyon, malign lezyonlarda ise geniş eksizyon ya da mastektomidir. Meme dokusunun ve meme başının korunması önemlidir. Rutin aksiller lenf nodu diseksiyonu önerilmemektedir(12,13). Serimizde tüm olgulara sirkumareolar insizyon ile lokal eksizyon yapılmıştır.

Sonuç olarak; çocukluk çağı meme kitlelerinin çoğu benigndir. Benign/malign ayrımında net radyolojik kriterler bulunmamaktadır. Şüpheli olgularda iğne biyopsisi doğru cerrahi planlanması için gereklidir. Histopatolojik bulgular cerrahi seçimi ve takip kriterleri için önemlidir.

8. Ezer SS, Oguzkurt P, Ince E, Temiz A, Bolat FA, Hicsonmez A. Surgical treatment of the solid breast masses in female adolescents. J Pediatr Adolesc Gynecol. 2013;26:31-5. [CrossRef]

9. Resetkova E, Khazai L, Albarracin CT, Arribas E. Clinical and radiologic data and core needle biopsy findings should dictate management of cellular fibroepithelial tumors of the breast. Breast J. 2010;16:57380. [CrossRef]

10. Ciftci AO, Tanyel FC, Büyükpamukçu N, Hiçsönmez A. Female breast masses during childhood: a 25-year review. Eur J Pediatr Surg. 1998;8:67-70. [CrossRef]

11. Komenaka IK, El-Tamer M, Pile-Spellman E, Hibshoosh H. Core needle biopsy as a diagnostic tool to differentiate phyllodes tumor from fibroadenoma. Arch Surg. 2003;138:987-90. [CrossRef]

12. Chang DS, McGrath MH. Management of benign tumors of the adolescent breast. Plast Reconstr Surg. 2007;120:13-9. [CrossRef]

13. Chen WH, Cheng SP, Tzen CY, Yang TL, Jeng KS, Liu CL, Liu TP. Surgical treatment of phyllodes tumors of the breast: retrospective review of 172cases. J Surg Oncol. 2005;91:185-94. [CrossRef] 